\title{
Experimental and Numerical Investigation on the Stability of Loess Embankment Treated by Chemical Solution under Freezing-Thawing Conditions
}

Hua Liu ( $\square$ liuhua029@xauat.edu.cn )

Xi'an University of Architecture and Technology

\section{Zelin Niu}

Xi'an University of Architecture and Technology

\section{Yuanhong Dong}

Xijing University

Naifei Liu

Xi'an University of Architecture and Technology

Shuocheng Zhang

Beijing Jiaotong University

\section{Research Article}

Keywords: loess embankment, freezing-thawing cycle, chemical solutions, safety factor, limit equilibrium methods

Posted Date: March 15th, 2021

DOI: https://doi.org/10.21203/rs.3.rs-286923/v1

License: (c) (i) This work is licensed under a Creative Commons Attribution 4.0 International License.

Read Full License 
Ethical Statement

Re: Experimental and Numerical Investigation on the Stability of Loess Embankment Treated by

4 Chemical Solution under Freezing-Thawing Conditions

5

I certify that this manuscript is original and has not been published and will not be submitted elsewhere for publication while being considered by Natural Hazards. And the study is not split up

8 into several parts to increase the quantity of submissions and submitted to various journals or to one 9 journal over time. No data have been fabricated or manipulated (including images) to support our 10 conclusions. No data, text, or theories by others are presented as if they were our own.

The submission has been received explicitly from all co-authors. And authors whose names appear on the submission have contributed sufficiently to the scientific work and therefore share collective responsibility and accountability for the results.

Part of the given authors' emails is in charge of submitting papers and communicating with the research partners. Some of them have not yet applied an institutional email.

I am sorry for any inconvenience that this may cause.

20 Yours sincerely,

Hua LIU

23 liuhua029@xauat.edu.cn

24 Ze-lin Niu 
30 We declare that we have no financial and personal relationships with other people or organizations 31 that can inappropriately influence our work, there is no professional or other personal interest of any 32 nature or kind in any product, service and/or company that could be construed as influencing the 33 position presented in, or the review of, the manuscript entitled.

34 
35 Experimental and Numerical Investigation on the Stability of Loess Embankment Treated by

36 Chemical Solution under Freezing-Thawing Conditions

38 Hua Liu ${ }^{1,2}$, Ze-Lin Niu ${ }^{1,2 *}$, Yuan-hong Dong ${ }^{3}$, Nai-fei Liu ${ }^{1,2}$, Shuo-Cheng Zhang ${ }^{4}$

401 School of Civil Engineering, Xi'an University of Architecture and Technology, Xi'an, China, $41 \quad 710055$

422 Shaanxi Key Laboratory of Geotechnical and Underground Space Engineering, Xi' an University of 43 Architecture and Technology, Xi'an, China, 710055;

443 Shaanxi Key Laboratory of Safety and Durability of Concrete Structures, Xijing University, Xi'an, 45 Shaanxi 710123, China;

464 School of Civil Engineering, Beijing Jiaotong University, Beijing, China, 100044

48 Corresponding author *: Ze-Lin Niu, School of Civil Engineering, Xi'an University of Architecture 49 and Technology, Xi'an, Shaanxi, 710055, China. Tel.: (+86) 18509256818.

$50 \quad$ E-mail: niuzldq@xauat.edu.cn

\section{List of notations}

$53 \quad \delta_{\mathrm{s}}$ is collapsible coefficient $\left(\delta_{\mathrm{s}}=0.015\right.$ is the evaluation criterion of collapsibility)

$54 \quad h_{0} \quad$ is initial height of the sample

$55 \quad h_{1} \quad$ is the stable height of the sample under a certain pressure

$56 \quad h_{2}$ is the level stable height of the sample after immersion under the same pressure

$57 \quad N \quad$ is the number of samples with safety factor less than 1

$58 M$ is the total number of samples

$59 \quad \beta_{\mathrm{s}} \quad$ is RI

$60 \mu_{\mathrm{s}}$ is average safety factor

$61 \sigma_{\mathrm{s}}$ is standard deviation of average safety factor 
Abstract: In order to study the influence of chemical solution on the stability of loess embankment in seasonally frozen regions, the compression index, shear strength index and embankment safety factor of compacted loess fillings that were treated by different concentrations of chemical solution were analyzed through laboratory test and slope stability analysis program. The experimental results showed that the collapsible coefficients of remolded loess treated by different chemical solution will all increase which comparing the distilled water, and then will change again after freezing-thawing cycles (FTCs). The compression index of undisturbed loess will show regularity with the increase of chemical solution concentration. The shear strength of remolded loess also changed under the chemical solution and FTCs. Besides, simulation of the strength parameters by limit equilibrium methods showed that the safety factor of loess embankment with treatment of solution was significantly higher than that of untreated one, and the FTC would cause a further deterioration. The embankment stability improved after treated by chemical solution without considering seepage of rainwater. These results would provide a novel method to the problem of embankment stability related to environmental condition changes.

Key words: loess embankment; freezing-thawing cycle; chemical solutions; safety factor; limit equilibrium methods

\section{Introduction}

Since the British chemist (SMITHRA, 1872) first reported the concept of acid rain, which has become one of the most important atmospheric environmental issues around the world, has caused disaster to people's health, corrosion of cultural relics, and destruction of ecosystems. Economic development and urban expansion of China have caused air pollution like acid rain to be very prominent (Zhang et al., 2007; Ouang et al., 2008). With development of the loess regions, the frequency of acid rain has changed year by year, which has led to engineering problems. Because the loess is mostly distributed in the seasonal frozen region, this problem will be more complex under the influence of FTCs.

The Loess Plateau $\left(34^{\circ} 00^{\prime}-45^{\circ} 05^{\prime} \mathrm{N}, 101^{\circ} 00^{\prime}-114^{\circ} 33^{\prime} \mathrm{E}\right)$ nearly covers a total area of $6.3 \times 10^{5} \mathrm{~km}^{2}$ and is located in Northern China. The Loess Plateau is the largest loess area in the world, with an elevation of 200-3000 $\mathrm{m}$ and a sedimentary thickness of 30-80 m (sometimes 150-180 m) (Zhao et al., 2016). The typical loess is an Aeolian deposit with an open and meta-stable structure, characterized by high porosity, low density, and silt-dominated particle size arranged in an open fabric supported by cementation bonds. Due to these characteristics, the loess deposit can show an abrupt collapse due to wetting and overburden pressure which causes geological and geotechnical hazards such as landslides, ground subsidence, differential settlement, and surface cracks leading to the failure of man-made 
infrastructures built on deposits of loess soil (Li et al., 2015; Derbyshire et al., 1995). With approving of the 'National Expressway Network Plan' and 'Mid-to-Long Term Railway Network Plan' in 2005 and 2008 respectively, the highspeed railways and highways in China have experienced a major growth and expansion ever since (Ma et al., 2017). In Northern China, due to loess's advantages of abundant supply and low cost, it has been widely used as fillings or foundation soil of various infrastructures ( $\mathrm{Li}$ et al., 2017). Therefore, the long-term exposure of loess embankment under natural environment was easily affected by change of temperature and humidity, and its engineering properties will change with time, which lead to various engineering problems. When a densely compacted loess is exposed to freezing, soil particles are separated by distinct ice lenses, causing macro-pores $(5 \sim 20 \mu \mathrm{m})$ and fissures inside. Besides, when the ice melts, larger pores and fissures are left (Mu et al., 2011; Zhang et al., 2015). The fabric of loess is destroyed, leading to instability and collapse of the embankment after repeated FTCs (Qi et al., 2006). The shortcomings such as the collapsibility of loess and its own advantages should be fully considered as problems in use of the roadbed after backfilling (Qi et al., 2008; Li et al., 2017).

The impact of FTCs on seepage (Zimmie et al., 1990; Kim et al., 1992), porosity (Benson et al., 1993; Eigenbrod, 1996), liquid and plastic limit (Viklander et al., 2000; Zhang et al., 2015) of soil has already studied by a large number of engineers, scholars and research groups all over the world. In order to put the theory into practice, more scholars began to consider the impact of the FTCs on infrastructures. In the study of secondary subsidence or multiple collapse of embankment, many scholars have suggested that it is caused by repeated wetting-drying, freezing-thawing, and salinization-desalinization cycles in seasonally frozen regions (Eigenbrod, 2001; Houston et al., 2001; Li et al., 2010; Li et al., 2011; Malusis et al., 2011; Chang et al., 2013; Zhang et al., 2013; Li et al., 2018). Li et al (2015) studied the microstructure and engineering characteristics of recompacted loess after freeze-thaw, wet-dry, and salinizationdesalinization cycles, they also analyzed the mechanism of multiple collapse of loess highway embankment. Özgan et al. (2015) compared and analyzed the physical indicators of soil samples before and after freezing and thawing. Besides, they used electron microscopy (SEM) tests and energy dispersion X-ray-EDX tests to observe the structure of samples, and performed triaxial compression tests on the soil samples to determine the mechanics of the soil samples. Meanwhile, these studies showed that the structure of some compacted loess was similar to that of undisturbed loess (Deng et al., 2010; Jiang et al., 2012; Liu et al., 2016). But in terms of the influence of acid rain on soil, most of studies focused on the impact on agriculture or environment. Some scholars have considered the stability of rock slope under acid rain. Zhao et al. (2009) simulated the formation of the sliding surface of the acid rain by testing the changes in the mineral composition and shear strength of the specimen after different soaking times. Their results showed not only the change of strength index but also the analysis of change in mineral composition. Finally, 
124 the chemical-mechanical model of clay was discussed. Zhao et al. (2019) taking the gabbro rock slope from a typical acid rain area in Ya'an city as an example, firstly designed a chemical-weathering simulation experiment for rocks affected by acid rain, and carried out research on the acid etching effect of gabbro structure with different penetration and acid rain duration. The direct shear test of the bulk structure and calculation of the slope stability were used to compare the slope stability under different acid rain duration conditions, and described the significant weakening effect of acid rain on the slope stability. However, engineering problems of loess such as slope stability or roadbed stability affected by external environment are still needed to be studied in seasonally frozen regions.

Previous studies on stability of soil embankment after freezing and thawing have yielded fruitful results, however, coupling the stability of embankment with chemical solution is a more complex issue. In order to study the effect of chemical solution on the stability of roadbed and embankment in seasonally frozen regions, the compressibility and shear strength of contaminated soil samples after freezing-thawing cycles were obtained. Moreover, the parameters obtained were used to simulate the stability of embankment, and to explore the roles which influence in the embankment under different conditions. This will provide a theoretical support for preventing embankment instability and collapse.

\section{Experimental Materials and Procedure}

\subsection{Material properties}

Fig. 1 shows the chosen locations in the survey area. According to Specifications for Monitoring of Acid Rain (GB T 19117-2003), the average PH value of the rainfall in Lueyang is 5.48, being less than 5.6, so the rainfall is acidic in 2012-2017. The minimum PH value reaches 3.8. The average PH value of rainfall in Yan' an is 5.76, falling between 5.6 and 7.0, so the rainfall is neutral. The average $\mathrm{PH}$ of rainfall in Yulin is 7.34, being greater than 7, so the rainfall is alkaline. Its highest $\mathrm{pH}$ value reaches 9.3 (Fig. 2). This shows that the situation of rainfall with various $\mathrm{pH}$ value is very common in the survey area. This also provides a basis for the following experimental study.

Fig. 1 Survey map

Fig. 2 Rainfall and its pH value for typical areas in Shaanxi Province in 2012-2017

Loess samples was located at $34^{\circ} 16^{\prime}$ N $108^{\circ} 54^{\prime} \mathrm{E}$, Shaanxi Province, Northwestern China. The reason for choosing this type of loess is that it has widely been used as highway or railway embankment. The loess was dried and sieved by a $2-\mathrm{mm}$ sieve. The basic physical parameters of the sampled soil can be seen in Table 1 . In this experiment, the 
procedures followed the specifications in the Chinese Geotechnical Test Method Standard (GBT50123-2019).

Table 1 Physical parameters and chemical composition of the loess and grain size distribution

\subsection{Sample preparation}

Sulfuric acid $\left(\mathrm{H}_{2} \mathrm{SO}_{4}\right)$ and sodium hydroxide $(\mathrm{NaOH})$ are commonly used in industry, and were selected as the chemical solution in this experiment. The water content was controlled at $20 \%$. The ring knife (inner diameter 61.8 $\mathrm{mm}$, height $20 \mathrm{~mm}$ and inner diameter $79.8 \mathrm{~mm}$, height $20 \mathrm{~mm}$ ) was used to make the recompacted soil samples after the standard compaction test and the intact soil samples for compression test and shear test. Sulfuric acid and sodium hydroxide solutions with concentration of $5 \%, 10 \%$ and $15 \%$ were added respectively to the loess samples for collapsibility test and direct shear test. Sulfuric acid and sodium hydroxide solutions with molar concentration of 0.1 $\mathrm{mol} / \mathrm{L}, 0.5 \mathrm{~mol} / \mathrm{L}$ and $2 \mathrm{~mol} / \mathrm{L}$ were added respectively to the soil for consolidation test. A group of soil samples moistened by distilled water was added for comparison of each samples.

\subsection{Freeze-thaw procedure}

The soil samples were frozen and thawed through the temperature test chamber. Each freeze-thaw cycle for freezing and thawing lasted for 8 hours (Fig. 3). The numbers of freeze-thaw cycle were 0, 1, 2, 5, 10, 15 and 20. According to the average temperature in the northwest region of China, the variation range of temperature was $\pm 20^{\circ} \mathrm{C}$ with an accuracy of $\pm 0.1^{\circ} \mathrm{C}$ (Zhang et al., 2020). In order to reduce random error, $4 \sim 8$ tests were repeated.

Fig. 3 Temperature change in the temperature test chamber

\section{Experiment Results}

\subsection{Compression characteristics}

Because of the high porosity, the collapsibility becomes one of the most remarkable characteristics of loess. The collapsibility of remolded loess after compaction as backfill is not obvious, but under the influence of external environment including change of temperature and moisture transfer, compressibility changes over time. Fig.4 shows the change of the collapsible coefficient of the remolded loess treated by different chemical solution through freezingthawing cycles at room temperature. After the freezing-thawing cycle, collapsible coefficient of the soil sample treated by acid-solution and the untreated soil sample become greater. The collapsible coefficient of soil sample treated by alkaline-solution becomes smaller. The collapsible coefficient can be obtained from Eq. (1). 


$$
\delta_{\mathrm{s}}=\frac{h_{1}-h_{2}}{h_{0}}
$$

182 Fig.5 and 6 show the change of compression of intact soil sample treated by different molar concentrations of acidic solution and alkaline solution. The smaller the compression of the soil, the higher the compressibility of the soil is.

Fig. 4 Collapsible coefficient of remolded loess under different conditions

Fig. 5 Constrained modulus of soil treated with $\mathrm{H}_{2} \mathrm{SO}_{4}$ solution

Fig. 6 Constrained modulus of soil treated with $\mathrm{NaOH}$ solution

190 It can be seen in Fig.5 that the compression of the soil samples treated with different molar concentration of acidic 191 solution increases under alow pressure $(200 \mathrm{kPa})$. As the pressure increases, the constrained of the soil samples 192 decreases and then increases. The soil sample treated with $0.1 \mathrm{~mol} / \mathrm{L}$ and $0.5 \mathrm{~mol} / \mathrm{L}$ acidic solutions starts to decrease at $200 \mathrm{kPa}$ and re-increases at $400 \mathrm{kPa}$. The soil sample treated with $2 \mathrm{~mol} / \mathrm{L}$ acidic solution starts to decrease at 100 $194 \mathrm{kPa}$ and re-increases at $200 \mathrm{kPa}$. The soil sample treated without chemical solution starts to decrease at $50 \mathrm{kPa}$ and re-increases at $100 \mathrm{kPa}$. Besides, the constrained of the soil sample increases with the decrease of the molar concentration of the acidic solution when the pressure is $12.5-800 \mathrm{kPa}$, but the phenomenon is opposite when the

198 The trend of compression of soil samples treated with alkaline solution is basically the same as that of acidic solution.

199 It increases first, then decreases and increases finally with the increasing of the pressure. The compression of soil sample treated with $0.1 \mathrm{~mol} / \mathrm{L}$ alkaline solution is very large when the pressure is less than $800 \mathrm{kPa}$. Followed by the soil sample without treated and soil sample treated with $0.5 \mathrm{~mol} / \mathrm{L}$ alkaline solution. The constrained modulus of soil sample treated with $2 \mathrm{~mol} / \mathrm{L}$ alkaline solution is the smallest, that is, the compressibility is the highest under this condition. The change in constrained modulus is exactly the opposite when pressure is greater than $800 \mathrm{kPa}$. The compressibility of the soil after treatment with chemical solution increases in the low-pressure zone $(<800 \mathrm{kPa})$ with the increase of the molar concentration of the solution, while the compressibility decreases with the increase of the molar concentration of the solution in the high-pressure zone $(>800 \mathrm{kPa})$.

\subsection{Shear strength characteristics}

The liquidity index of soil increases with the increase of concentration of solution (shown as Fig. 7). Besides, the liquidity index of soil sample treated with alkaline solution is greater than that of acidic solution at the same 
concentration. Moreover, the liquidity index of soil sample treated with chemical solution is significantly greater than

211 that of the untreated one. The liquidity index of untreated soil is 0.176 , and the liquidity index of the soil treated with 212 acidic and alkaline solution at the concentration of $5 \%$ is 0.267 and 0.280 , respectively. The soil liquidity index of 213 soils treated with acidic and alkaline solutions at concentration of $10 \%$ is 0.317 and 0.355 , respectively. In addition, 214 they were 0.353 and 0.375 when the concentration is $15 \%$.

Fig. 7 Relationship between liquidity index and concentration of solution

217 The main reason for this phenomenon is that the water generated by the chemical reactions between soil sample with acidic and alkaline solution are different. According to the chemical composition of soil sample measured in the test, only the $\mathrm{SiO}_{2}$ and $\mathrm{Al}_{2} \mathrm{O}_{3}$, which account for about $72 \%$ of the total, eacted? with sodium hydroxide solution. When the concentration of the chemical solution is the same, more water generates at this time, and the water content varies with increase of chemical concentration (shown as Eq. (2) and (3))

$$
\begin{aligned}
& \left\{\begin{array}{l}
2 \mathrm{NaOH}+\mathrm{SiO}_{2}=\mathrm{Na}_{2} \mathrm{SiO}_{3}+\mathrm{H}_{2} \mathrm{O} \\
2 \mathrm{NaOH}+\mathrm{Al}_{2} \mathrm{O}_{3}=2 \mathrm{Na}_{2} \mathrm{AlO}_{3}+\mathrm{H}_{2} \mathrm{O}
\end{array}\right. \\
& \left\{\begin{array}{l}
\mathrm{H}_{2} \mathrm{SO}_{4}+\mathrm{CaO}=\mathrm{CaSO}_{4}+\mathrm{H}_{2} \mathrm{O} \\
3 \mathrm{H}_{2} \mathrm{SO}_{4}+\mathrm{Al}_{2} \mathrm{O}_{3}=\mathrm{Al}_{2}\left(\mathrm{SO}_{4}\right)_{3}+3 \mathrm{H}_{2} \mathrm{O} \\
3 \mathrm{H}_{2} \mathrm{SO}_{4}+\mathrm{Fe}_{2} \mathrm{O}_{3}=\mathrm{Fe}_{2}\left(\mathrm{SO}_{4}\right)_{3}+3 \mathrm{H}_{2} \mathrm{O} \\
\mathrm{H}_{2} \mathrm{SO}_{4}+\mathrm{MgO}=\mathrm{MgSO}_{4}+\mathrm{H}_{2} \mathrm{O}
\end{array}\right.
\end{aligned}
$$

The strength of the soil increases with concentration of the chemical solution. After the freeze-thaw cycle, it deteriorates remarkably. However, although the strength of the soil treated with chemical solution after the freezethaw cycle deteriorates, the final strength is still greater than that of the soil sample moistened by distilled water. Besides, the strength of the soil treated with alkaline solution is greater than that of the soil treated with the acidic solution. As shown in Table 2, when soil sample did not undergo the freeze-thaw cycle, the strength of soil sample moistened by distilled water is $143.71 \mathrm{kPa}$, and the strength after contamination with $15 \%$ acid and alkali solutions are 227.4 and $254.37 \mathrm{kPa}$, respectively. After 20 freeze-thaw cycles, the shear strength in the above three cases are reduced to $115.89,212.71$, and $171.52 \mathrm{kPa}$, respectively.

Table 2 Shear strength under different conditions, $\mathrm{kPa}$

\section{Stability on Loess Embankment Slopes}

\subsection{Numerical Model}


An embankment along a highway in the loess area is selected as research object. The simulation model is obtained according to an instance of roadbed size and its stress. The model is divided into four layers, namely backfill, $\mathrm{Q}_{4}$

238 loess, $\mathrm{Q}_{3}$ loess and $\mathrm{Q}_{2}$ loess. Dimensions and load conditions of the model are shown in Fig.8. The boundary conditions are horizontally constrained on the left and right sides. The bottom is fixed and the rest are free boundaries. According to the data obtained in the above lab experiment and analogous to the physical and mechanical parameters of other similar geotechnical engineering, the parameters in this simulation are determined, as shown in Table 3. According to rainfall and frozen soil in loess area, the depth of influence is selected as $1.5 \mathrm{~m}$.

Fig. 8 The simulation model of loess embankment

Table 3 Mechanical parameters at different layers

\subsection{Change in safety factor}

Fig.9 shows the stability of embankment after freeze-thaw cycle. The slip surface with a safety factor less than 1 after screening is given. The smallest safety factor is only 0.859 . Therefore, it can be found that after multiple freeze-thaw cycles, the stability of the embankment will seriously deteriorate and the strength will significantly reduce. This seriously jeopardizes the safety and stability of highway embankment in loess area

Fig. 9 Safety factor of embankment after freeze-thaw cycle

The depth of infiltration in the loess area does not exceed $1.5 \mathrm{~m}$. The infiltration depth of the large-porosity loess model is $1.3 \mathrm{~m}$. (Tong et al., 2017). The strength of the soil after treated by acid or alkaline solution has changed significantly. The safety factor of acid-polluted embankment increased from 1 to 1.416 with an increase of $64.8 \%$. stability of embankment. Therefore, the analysis in this paper is only carried out under steady conditions.

(a) Acidic solution 
Fig. 10 Simulating slope safety factor after pollution

\subsection{Results analysis}

The safety factor $\left(F_{\mathrm{S}}\right)$ of the minimum slip surface is obtained from the analysis of slope stability. In addition to the $F_{\mathrm{S}}$, another important parameter is the average safety factor, which is obtained through a probabilistic analysis of all slip surfaces. The probability of failure, i.e., $P F$, is obtained by Eq. (4).

$$
P F=\frac{N}{M} \times 100 \%
$$

The reliability index (RI), not only characterizes the slope stability but also separates the average safety factor from the safety factor (shown as Eq. (5)). Detailed results under each condition are shown in Table 4.

Table 4 Summary of probabilistic analysis under different conditions

$$
\beta_{\mathrm{s}}=\frac{\mu_{\mathrm{s}}-1}{\sigma_{\mathrm{s}}}
$$

As shown in Fig.11, the gray columns indicate a safety factor of less than 1, and the rest is greater than 1 . That is to say, only under the conditions of freezing and thawing cycles, the soil will theoretically have a large degree of slope instability, and the stability of the soil slope after treated by acidic or alkaline solution is enhanced. The safety factor has no slip surface less than 1 , so the slope is relatively stable.

For the slope stability by the Simplified Bishop Method, "960/1000" indicates that 960 of the 1000 calculated samples have a safety factor less than 1, which is equivalent to a $96.5 \%$ probability of slope failure. Except for embankment under freeze-thaw cycle, the gray column does not appear under other conditions, so there is no need to take the $P F$ into consideration when the embankment affected by acid or alkaline solution. The frequency of safety factor of embankment affected by acid or alkaline solution appears to be the same, reaching its maximum value between 1.4 and 1.6, while the safety factor of embankment after freezing and thawing reach its maximum value at about 0.9 .

Fig. 11 The safety factor and its ralative frequency in different conditions

In general, convergence graph can illustrate the result of probability analysis and relatively stable value, such as the $P F$ or the average safety factor. If the value is not stable in convergence graph, the number of samples needs to be increased. As shown in Fig. 12, the convergence of average safety factor and $P F$ under normal condition are analyzed. It can be clearly found that two of them distribute symmetrically. In general, the safety factor of embankment is all greater than 1 . What's more, the safety factor decreases first, then increases and finally gets stable at around 25 with 
increase of samples. The trend of embankment of $P F$ increases at first, then decreases and finally stabilizes at around $32 \%$ with increase of samples. It shows that the embankment has a good stability without external influence.

Fig. 12 Convergence graph of average safety factor and probability of failure of normal embankment

The convergence graph can be used to determine whether the probability analysis converges to a final answer and whether more samples are needed. As shown in Fig.12 and 13, the safety factors of embankment no longer fluctuate significantly after reaching a steady state when the number of samples is around 200. After reaching an all-time high, they decrease and eventually reach a steady state. The safety factor of the embankment after freeze-thaw cycles reaches its peak earlier, and the subsequent variation is not very obvious. The safety factor of embankment affected by acid or alkaline solution increases with increase of the number of samples and is greater than 1 . This means that the embankment affected by acid or alkaline solution is more stable than that subjected to the freeze-thaw cycles.

Fig. 13 Convergence graph of safety factor of embankment under different conditions

Fig. 14 Convergence graph of $P F$ of embankment under freeze-thaw cycles

It can be found in Fig. 12 and 14 that the $P F$ of normal embankment starts from 0 and increases first and then decreases

312 Therefore, the influence of freeze-thaw cycle on the stability of embankment of backfilled roadbed affected by 313 chemical solution can't be ignored. It should be noted that the analysis of stability did not take the infiltration and 314 erosion of water into consideration. The impact will only be improved in the case of analysis of the final state. 315 Although the $\mathrm{pH}$ value of the rainfall is somewhat different from the solution used in the test, the impact of the longterm rainfall on the roadbed can't be ignored.

\section{5. Conclusion}

318 In order to study the effect of chemical solution on stability of loess embankment in seasonally frozen regions, indoor compression test and strength test were used to investigate the remodeled and undisturbed loess treated by chemical solution after freeze-thaw cycle. The stability of embankment after the change of soil properties was simulated by the limit equilibrium method. The following conclusions are obtained:

1) The collapsible coefficient of remolded loess after treatment with chemical solution will increase. After freeze- 
thaw cycle, the collapsible coefficient of soil samples without treated and treated with acidic solution will continue to increase, and the collapsible coefficient of soil sample treated with alkaline solution will decrease slightly.

2) The compression of the soil sample treated with chemical solution increases slightly then decreases with the increase of the molar concentration of solution when it is less than $800 \mathrm{kPa}$. When the pressure is greater than 800 $\mathrm{kPa}$, the compression increases rapidly, and it increases with increase of molar concentration of solution. The soil untreated has a small constrained modulus at pressures less than $800 \mathrm{kPa}$ and gradually reaches maximum as pressure increases.

3) Without considering the infiltration of water, chemical solution will increase the safety factor of the embankment. In areas where the embankment is unstable, due to long-term freeze-thaw cycles, it is conceivable to use chemical solution to improve the stability of the embankment of backfilling.

\section{Acknowledgements}

The research is supported by the National Natural Science Foundation of China (No. 51608436, No. 42071083),

Shaanxi Natural Science Foundation (2019JQ756), Special Scientific Research Project of Shaanxi Education Department (19JK0452) and China Postdoctoral Science Foundation (2019M663648).

\section{Conflict of Interest:}

The authors declare that they have no conflict of interest.

\section{References}

Benson CH, Othman M A (1993) Hydraulic conductivity of compacted clay frozen and thawed in situ. Journal of Geotechnical Engineering ASCE 119(2): 276-294, https://doi.org/10.1061/(ASCE)0733-9410(1993)119:2(276) Chang D, Liu JK (2013) Review of the influence of freeze-thaw cycles on the physical and mechanical properties of soil. Sciences in Cold and Arid Regions 5(4): 457-460, https://doi.org/10.3724/SP.J.1226.2013.00457

Deng J, Wang L, Zhang Z, Bing H (2010) Microstructure characteristics and forming environment of late Quaternary Period loess in the Loess Plateau of China. Environmental Earth Sciences 59(8):1807-1817, https://doi.org/10.1007/s12665-009-0162-x

Derbyshire E, Meng X, Wang JT, Zhou AQ, Li B (1995) Collapsible Loess on the Loess Plateau of China// Genesis and Properties of Collapsible Soils. International Journal of Rock Mechanics and Mining Sciences 33(4): $267-$ 293, https://doi.org/10.1016/0148-9062(96)85026-1

Eigenbrod KD (1996) Effects of cyclic freezing and thawing on volume changes and permeability of soft fine-grained soils. Canadian Geotechnical Journal 33(4):529-537. https://doi.org/10.1139/t96-079-301

Eigenbrod KD (2001) Geological hazards in loess terrain, with particular reference to the loess regions of China. Earth-Science Reviews 54(1-3):231-260, https://doi.org/10.1016/S0012-8252(01)00050-2

Houston SL, Houston WN, Zapata C, Lawrence C (2001) Geotechnical engineering practice for collapsible soils. Geotechnical and Geological Engineering 19:333-355, https://doi.org/10.1007/978-94-015-9775-3 6

Jiang M, Hu H, Liu F (2012) Summary of collapsible behaviour of artificially structured loess in oedometer and 
triaxial wetting tests. Canadian Geotechnical Journal 49(10):1147-1157, https://doi.org/10.1139/T2012-075

Kim WH, Daniel DE (1992) Effects of freezing on hydraulic conductivity of compacted clay. Journal of Geotechnical Engineering ASCE 118(7):1083-1097, https://doi.org/10.1061/(ASCE)0733-9410(1992)118:7(1083)

Li GY, Ma W, Jin HJ, Sheng Y, Niu FJ, Mu YH (2010) Experimental research on impact of freeze-thaw cycle on geotechnical properties of compacted loess. In: Proceedings of the 63rd Canadian Geotechnical \& 6th Canadian Permafrost Conference, Alberta, Canada: 431-435.

Li GY, Ma W, Mu YH, Wang F, Fan SZ, Wu YH (2017) Effects of freeze-thaw cycle on engineering properties of loess used as road fills in seasonally frozen ground regions, North China. Journal of Mountain Science 14(2):356-368, https://doi.org/10.1007/s11629-016-4005-4

Li GY, Ma W, Mu YH, Zhou CL, Mao YC (2011) Process and mechanism of impact of freezing and thawing cycle on collapse deformation of compacted loess, China Journal of Highway and Transport 24(5):1-5. (in Chinese)

Li GY, Ma W, Wang F, Fortier R, Wu YH, Mao YC, Hou X (2015) Processes and mechanisms of multi-collapse of loess roads in seasonally frozen ground regions: A review. Sciences in Cold and Arid Regions 4:456-468, https://doi.org/10.3724/SP.J.1226.2015.00456

Li G, Wang F, Ma W, Fortier R, Mu YH, Mao YC, Huo X (2018) Variations in strength and deformation of compacted loess exposed to wetting-drying and freeze-thaw cycles. Cold Region Science and Technology 151:159-167, https://doi.org/10.1016/j.coldregions.2018.03.021

Liu Z, Liu F, Ma F, Wang M, Bai XH, Zheng YL, Yin H, Zhang GP (2016) Collapsibility, composition, and microstructure of a loess in China. Canadian Geotechnical Journal 53(4):673-686, https://doi.org/10.1139/cgj2015-0285

Ma F, Yang J, Bai X (2017) Water Sensitivity and Microstructure of Compacted Loess, Transportation Geotechnical 11:41-56. https://doi.org/10.1016/j.trgeo.2017.03.003

Malusis MA, Yeom S, Evans JC (2011) Hydraulic conductivity of model soil-bentonite backfills subjected to wetdry cycling. Canadian Geotechnical Journal 48(8):1198-1211, https://doi.org/10.1139/t11-028

Mu YH, Ma W, Li GY, Mao YC (2011) Quantitative analysis of impacts of freeze-thaw cycles upon microstructure of compacted loess. Chinese Journal of Geotechnical Engineering 33(12):1919-1925.

Ouyang XJ, Zhou GY, Huang ZL, Liu JX, Zhang DQ, Li J (2008) Effect of simulated acid rain on potential carbon and nitrogenm ineralization in forest soils. Pedosphere 18(4):503-514, https://doi.org/10.1016/S10020160(08)60041-7

Özgan E, Serin S, Ertürk S, Vural I (2015) Effects of freezing and thawing cycles on the engineering properties of soils. Soil Mechanics and Foundation Engineering 52:95-99, https://doi.org/10.1007/s11204-015-9312-1

Qi J, Ma W, Song C (2008) Influence of freeze-thaw on engineering properties of a silty soil. Cold Region Science and Technology 53(3):397-404, https://doi.org/10.1016/j.coldregions.2007.05.010

Qi J, Vermeer Pa, Cheng G (2006) A review of the influence of freeze-thaw cycles on soil geotechnical properties. Permafrost and Periglacial Processes 53(3):245-252, https://doi.org/10.1016/j.coldregions.2007.05.010

Smith AR (2017) Air and rain: the beginnings of a chemical climatology. London: Longmans, Green, and C o.

Tong X, Peng JB, Zhu XH, Ma PH (2017) Advantage infiltration depth of rainfall in loess area. Bulletin of Soil and Water Conservation 3:231-236.

Viklander P, Eigenbrod KD (2000) Stone movements and permeability changes in till caused by freezing and thawing. Cold Region Science and Technology 31(2):151-162, https://doi.org/10.1016/S0165-232X(00)00009-4

Zhang FY, Wang GH, Kamai T, Chen WW, Zhang DX, Yang J (2013) Undrained shear behavior of loess saturated with different concentrations of sodium chloride solution. Engineering Geology 155(14):69-79, https://doi.org/10.1016/j.enggeo.2012.12.018

Zhang JE, Ouyang Y, Ling DJ (2007) Impacts of simulated acid rain on cation leaching from the Latosol in south 
China. Chemosphere 67(11):2131-2137, https://doi.org/10.1016/j.chemosphere.2006.12.095

Zhang SC, Liu H, Chen WH, Niu FJ, Niu ZL (2020) Strength deterioration model of remolded loess contaminated with acid and alkali solution under freeze-thaw cycles. Bulletin of Engineering Geology and the Environment, https://doi.org/10.1007/s10064-019-01721-w

Zhang Y, Bing H, Yang CS (2015) Influences of freeze-thaw cycles on mechanical properties of silty clay based on SEM and MIP test. Chinese Journal of Rock Mechanics and Engineering 34:3597-3603.

Zhao CL, Shao MA, Jia XX, Zhang C (2016) Particle size distribution of soils $(0-500 \mathrm{~cm})$ in the Loess Plateau, China. Geoderma Reg 7(3):251-258, https://doi.org/10.1016/j.geodrs.2016.05.003

Zhao XY, Li KP, Li X, Xiao D (2019) Experimental study on mechanism of acid rain-induced slide of gabbro rock slope. Journal of Engineering Geology ASCE 1:155-164.

Zhao Y, Cui P, Hu LB (2009) Relation between evolution of clay shear strength and landslide induced by acid raintaking landslides in Three gorges reservoir area for example. Chinese Journal of Rock Mechanics and Engineering 3:576-582.

Zheng Y, Ma W, Mu YH, Bing H (2015) Analysis of soil structures and the mechanisms under action of freezing and thawing cycles. In: Proceeding of Sixteenth International Conference on Cold Regions Engineering, ASCE, Salt Lake City, Utah.

Zimmie TF, Laplante C (1990) The effect of freeze-thaw cycles on the permeability of a fine-grained soil. Hazardous and Industrial Waste 22:580-593. 
Figures

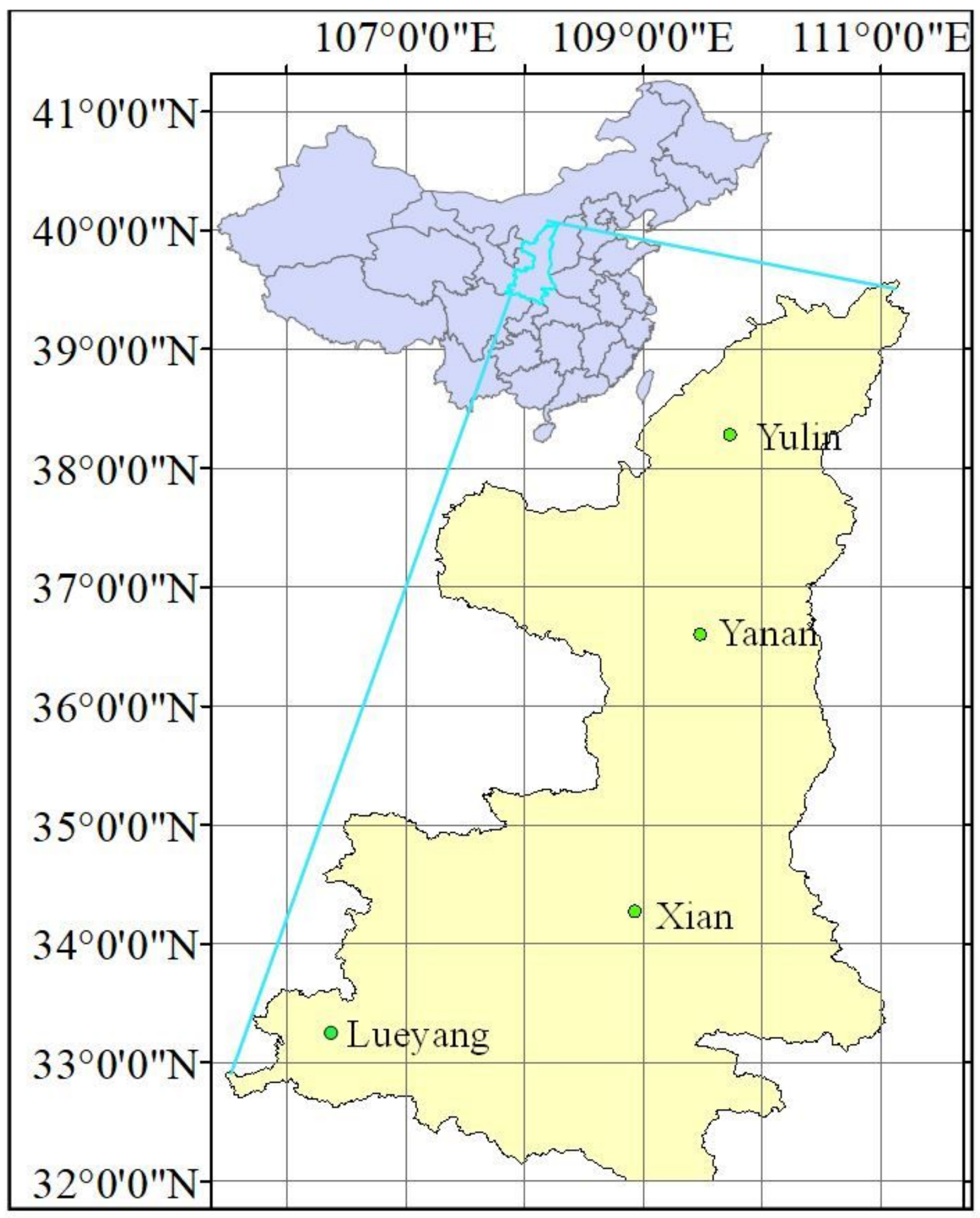

Figure 1

A map for the survey area. Note: The designations employed and the presentation of the material on this map do not imply the expression of any opinion whatsoever on the part of Research Square concerning 
the legal status of any country, territory, city or area or of its authorities, or concerning the delimitation of its frontiers or boundaries. This map has been provided by the authors.
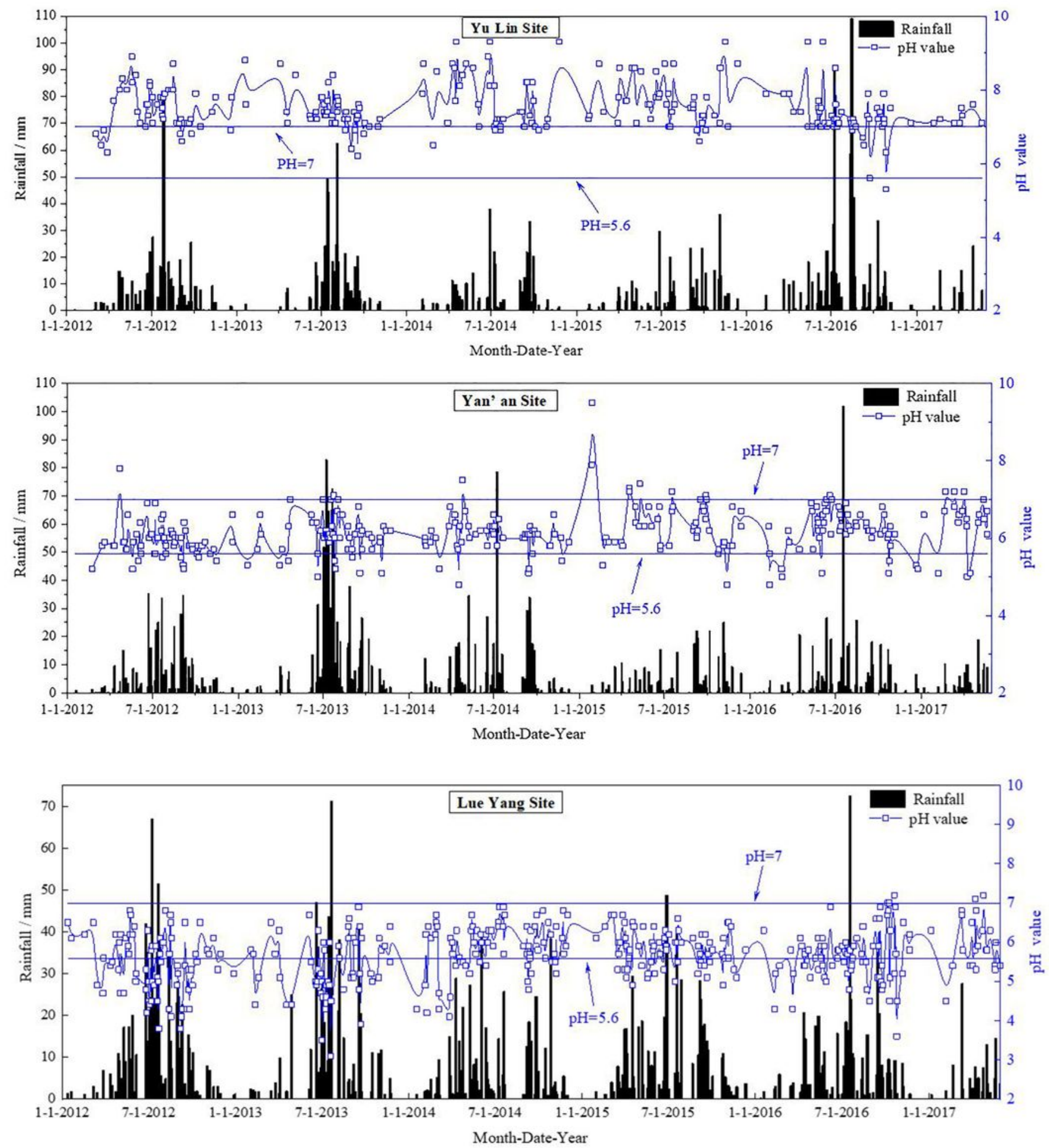

Figure 2

Rainfall and its pH value of typical areas in Shaanxi Province in 2012-2017 

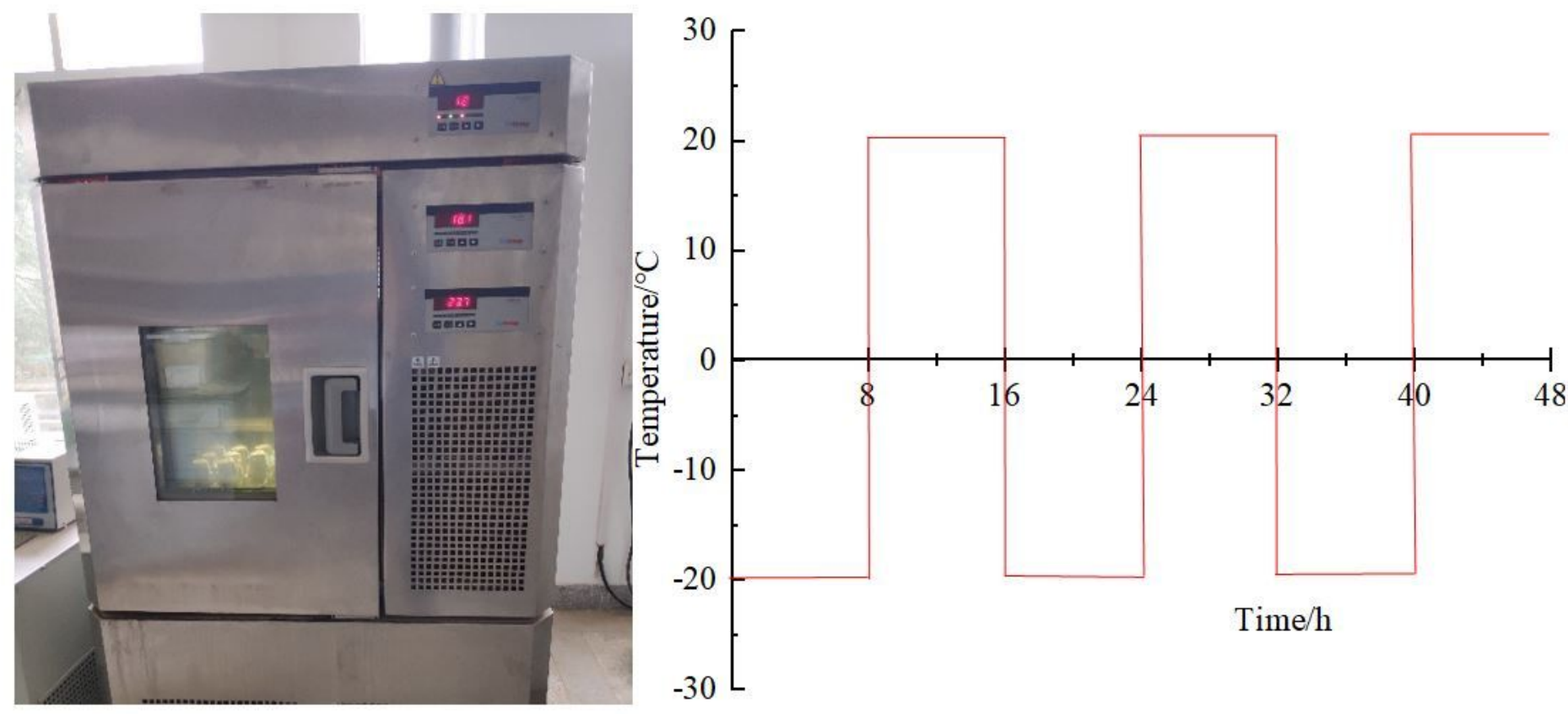

Figure 3

Temperature change in the temperature test chamber

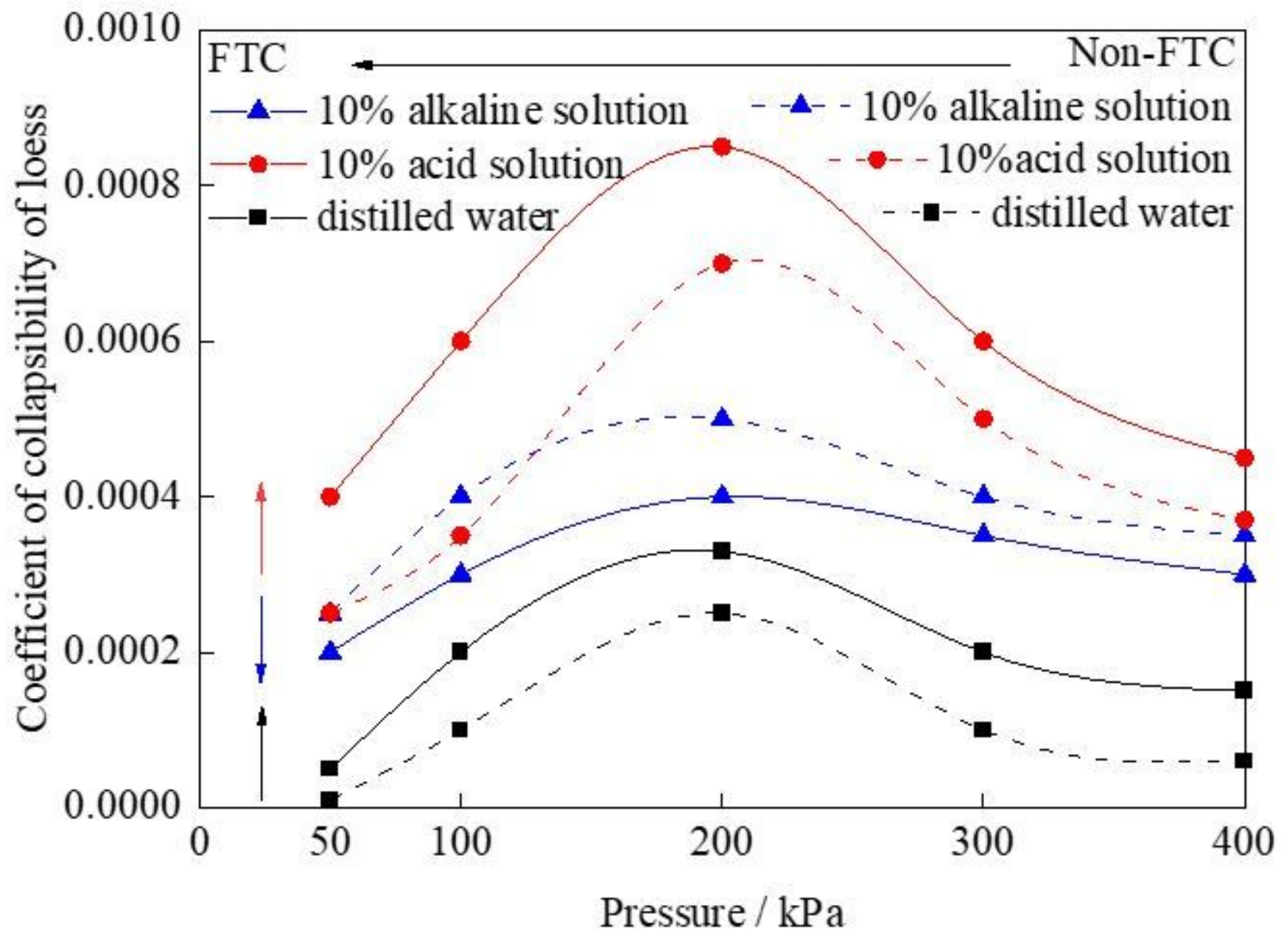


Figure 4

Collapsible coefficient of remolded loess under different conditions

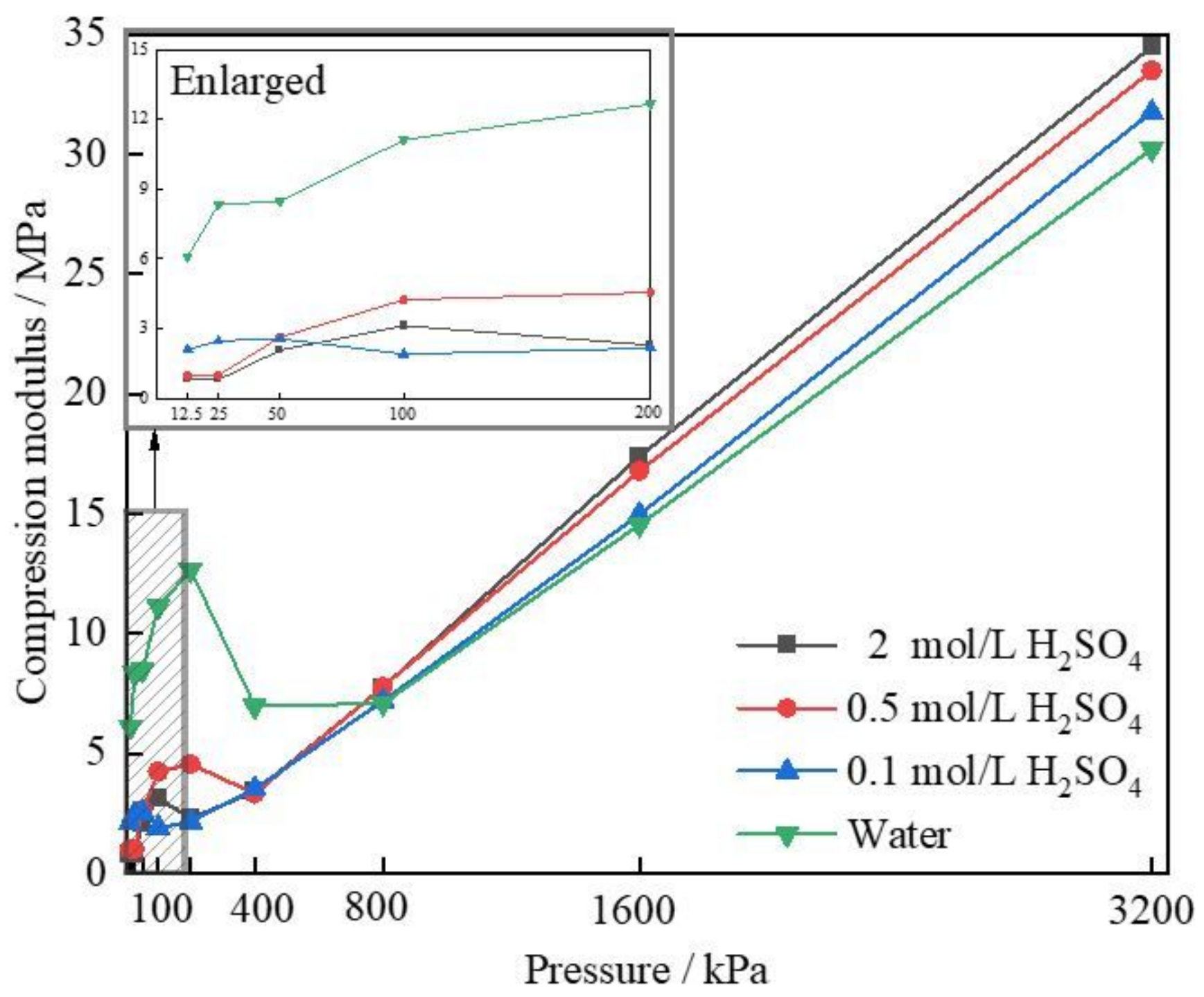

Figure 5

Constrained modulus of soil treated with $\mathrm{H} 2 \mathrm{SO} 4$ solution 


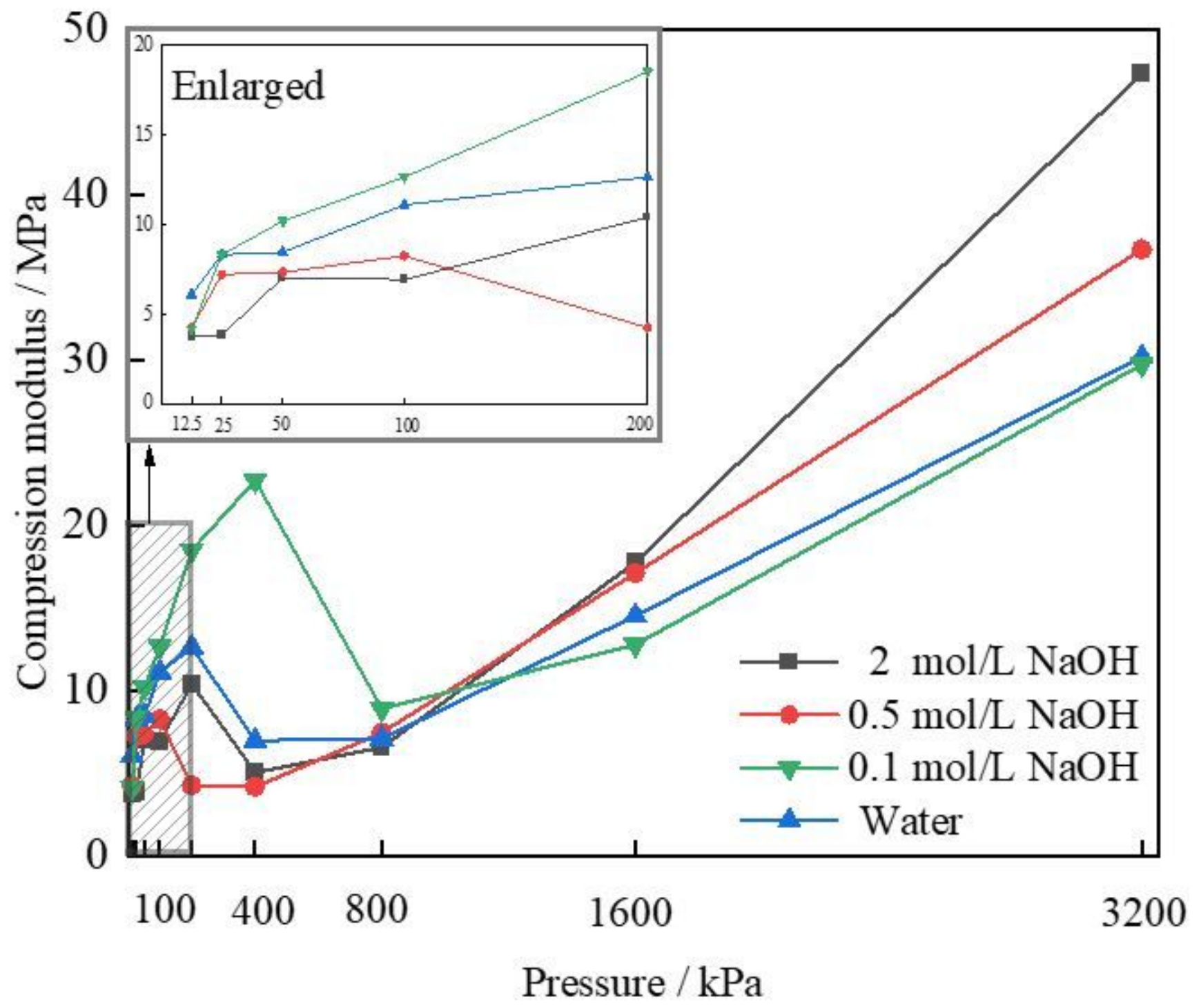

Figure 6

Constrained modulus of soil treated with $\mathrm{NaOH}$ solution 


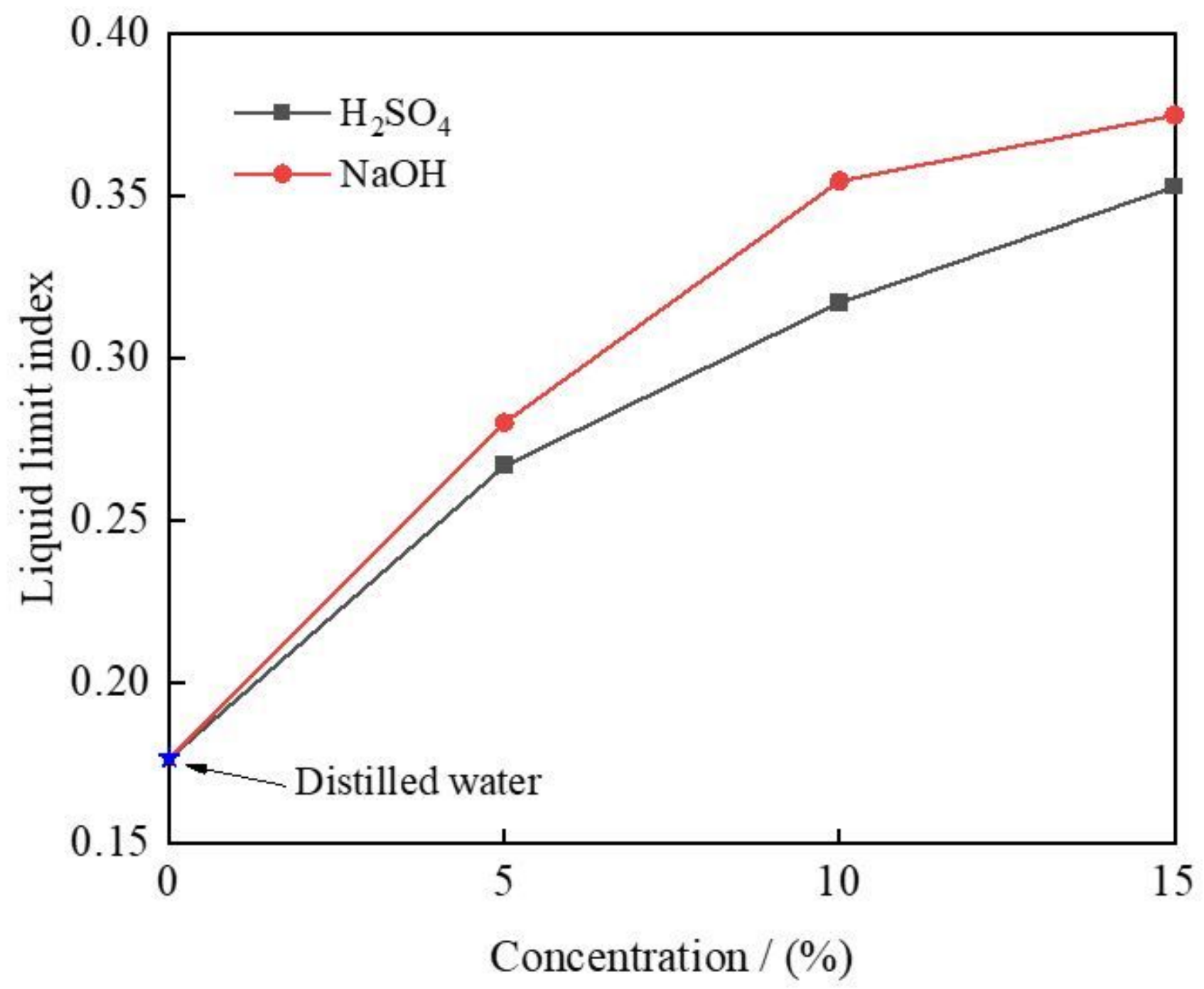

Figure 7

Relationship between liquidity index and concentration of solution 


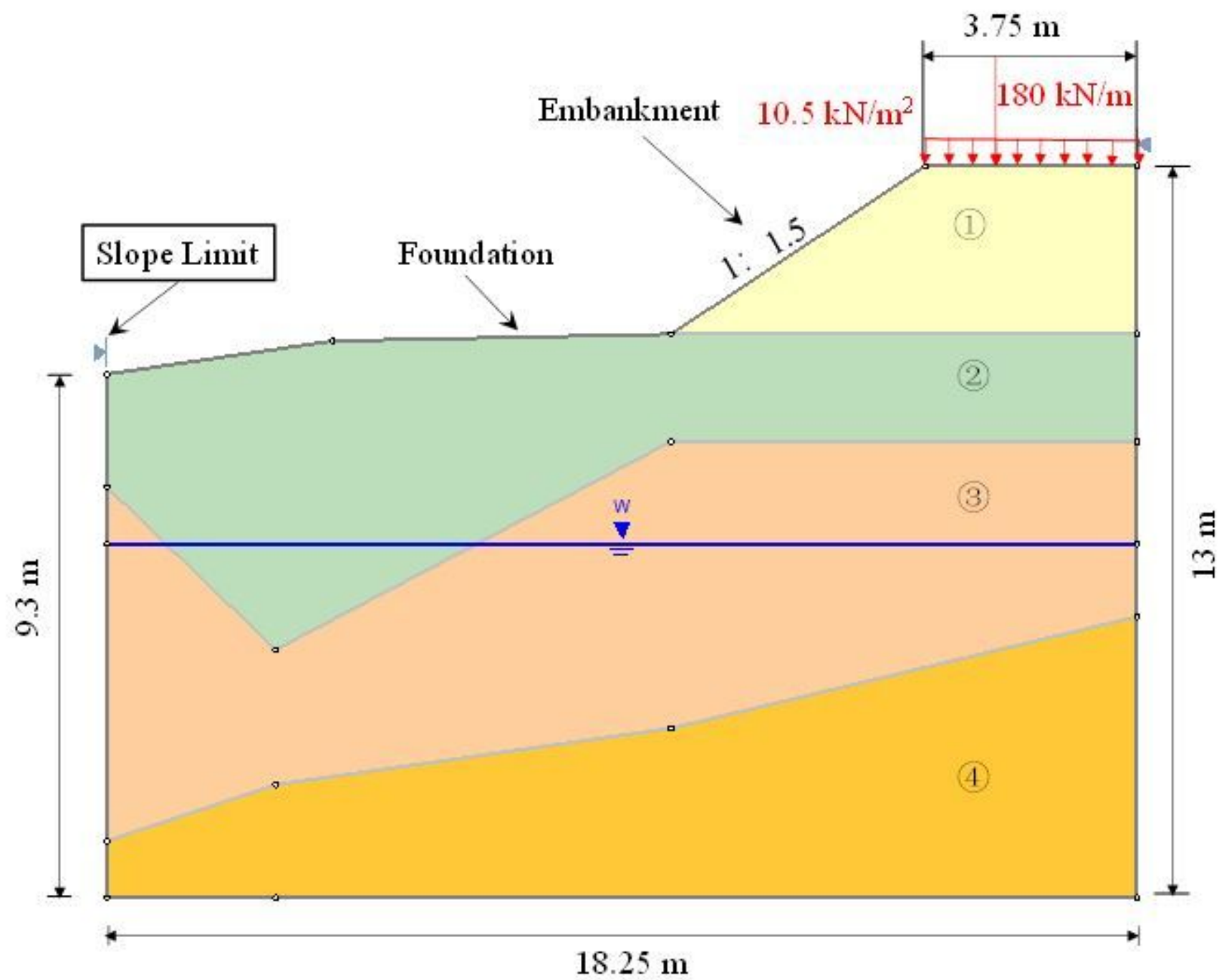

Figure 8

The simulation model of loess embankment 


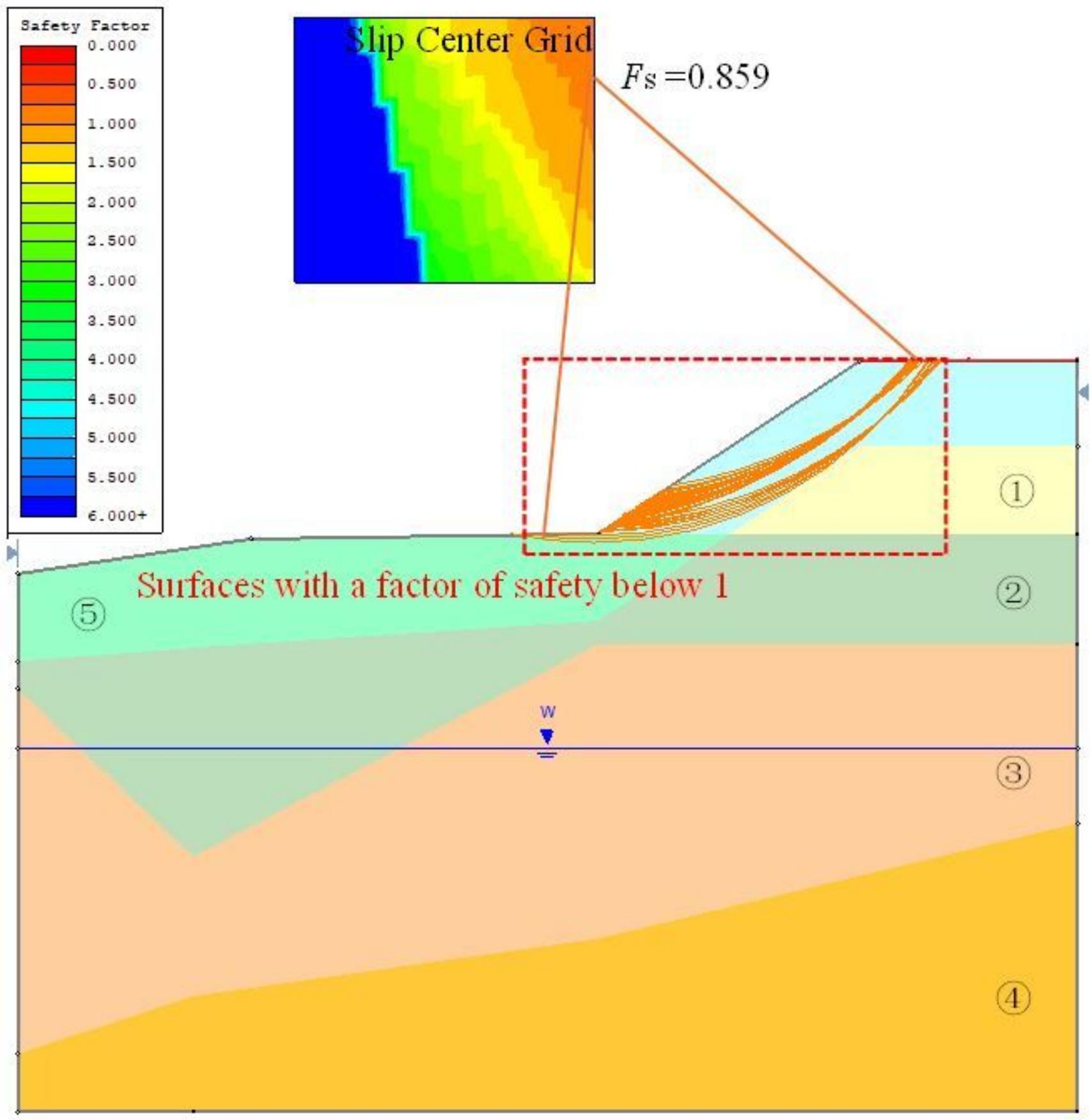

Figure 9

Safety factor of embankment after freeze-thaw cycle 


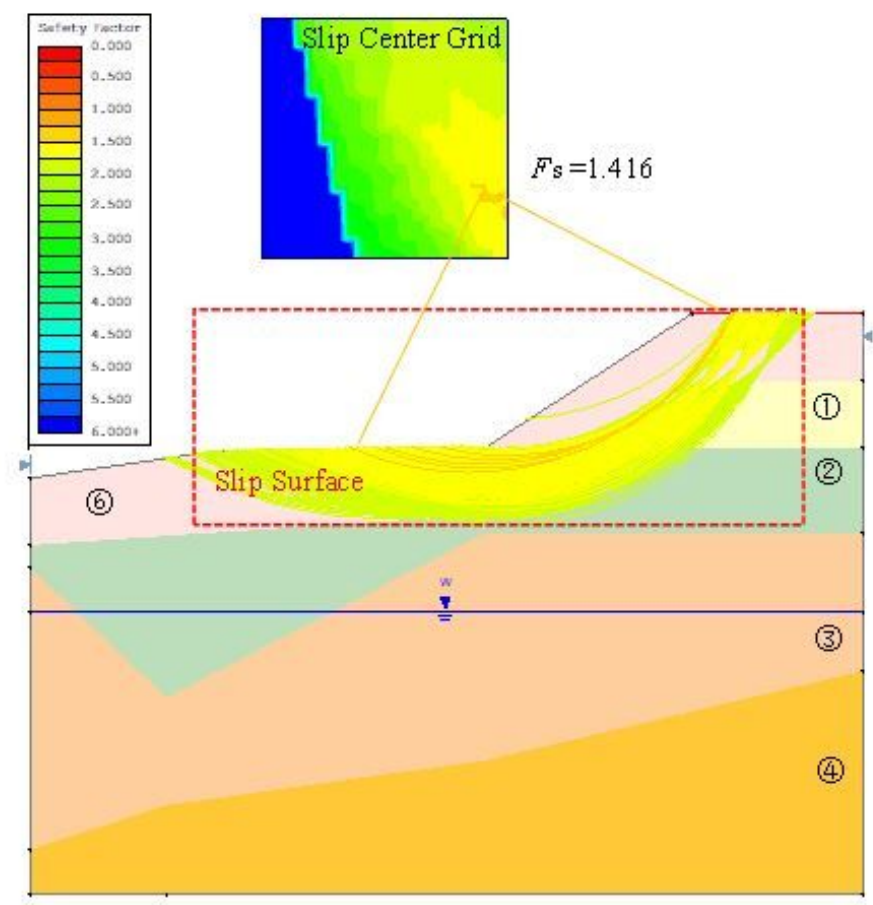

(a) Acidic solution

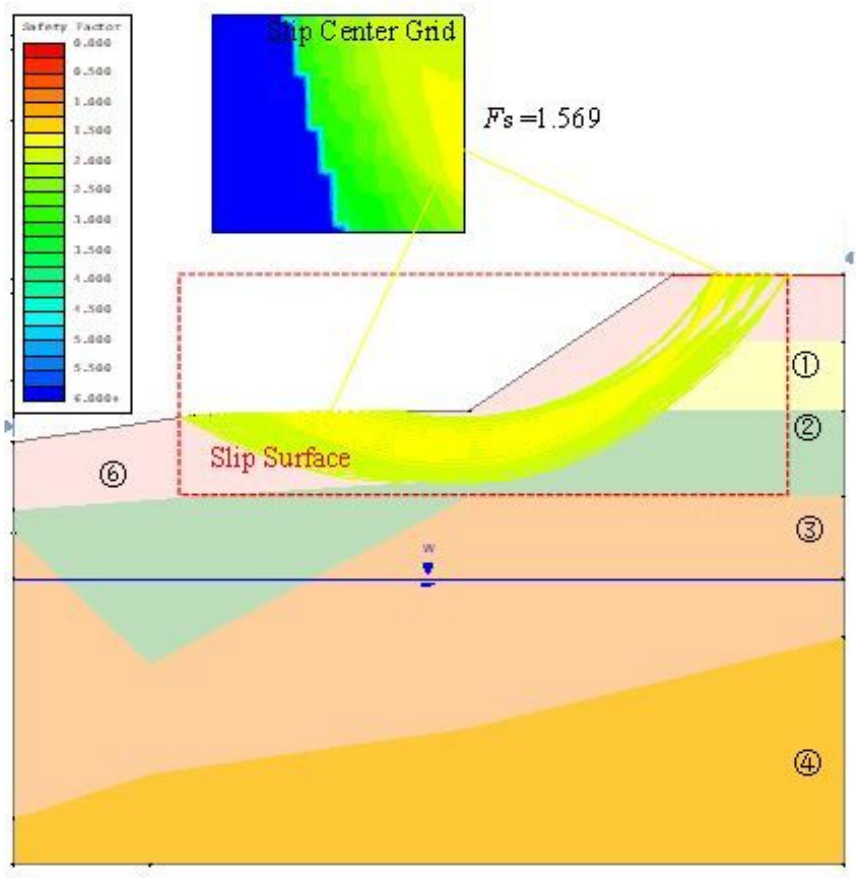

(b) Alkaline solution

Figure 10

Simulating slope safety factor after pollution (a) Acidic solution (b) Alkaline solution 


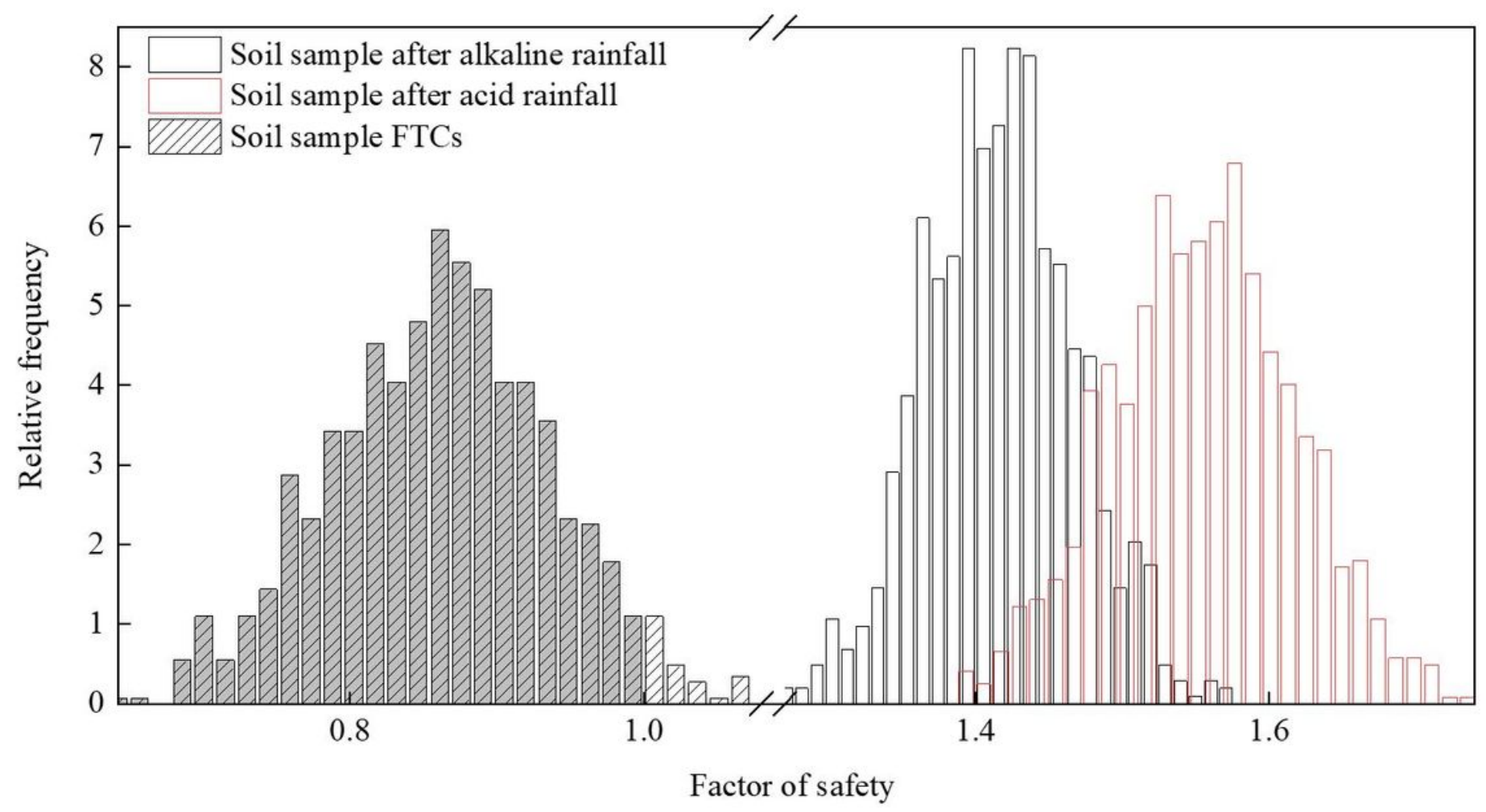

Figure 11

The safety factor and its relative frequency in different conditions

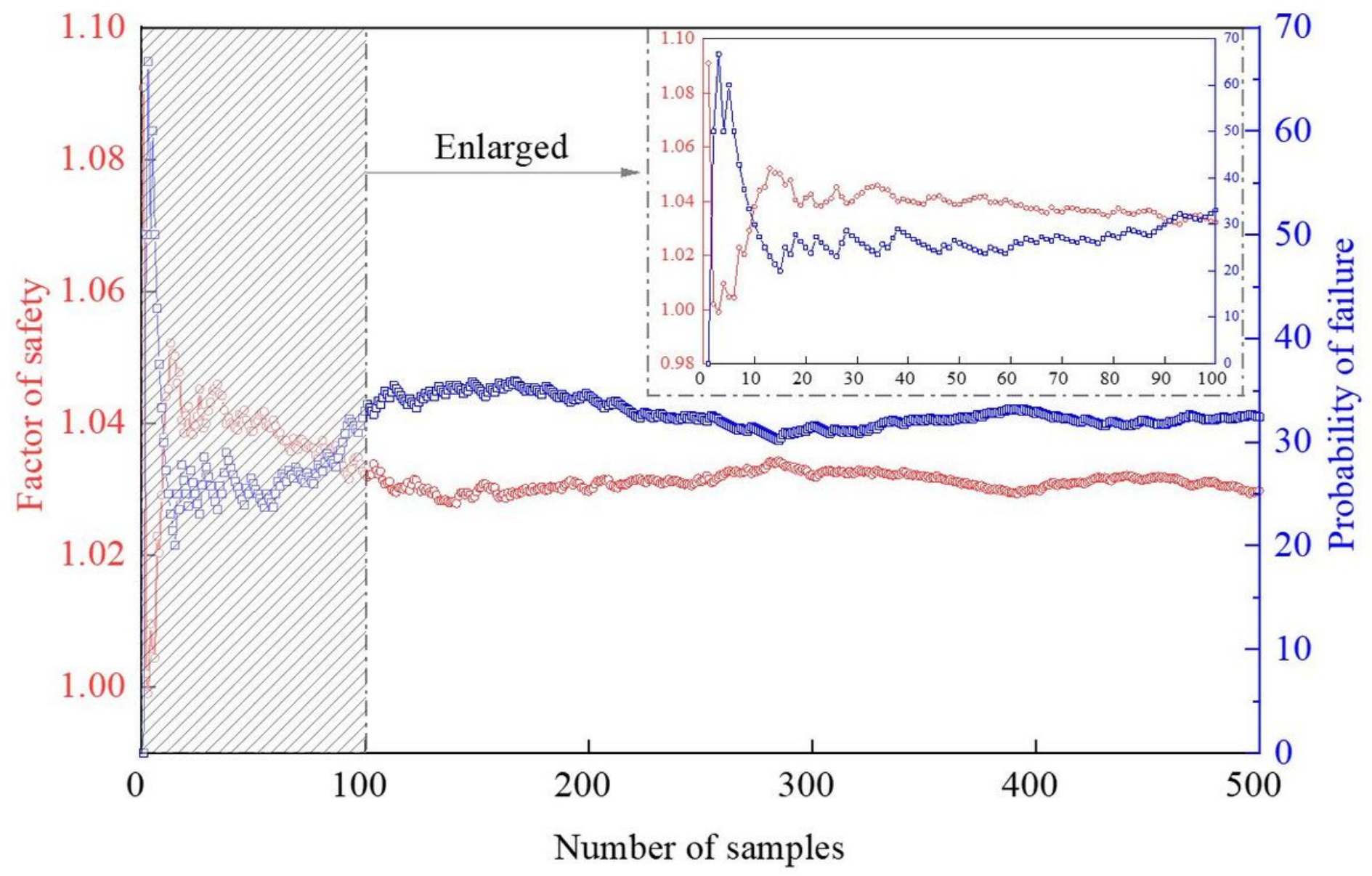


Figure 12

Convergence graph of average safety factor and probability of failure of normal embankment

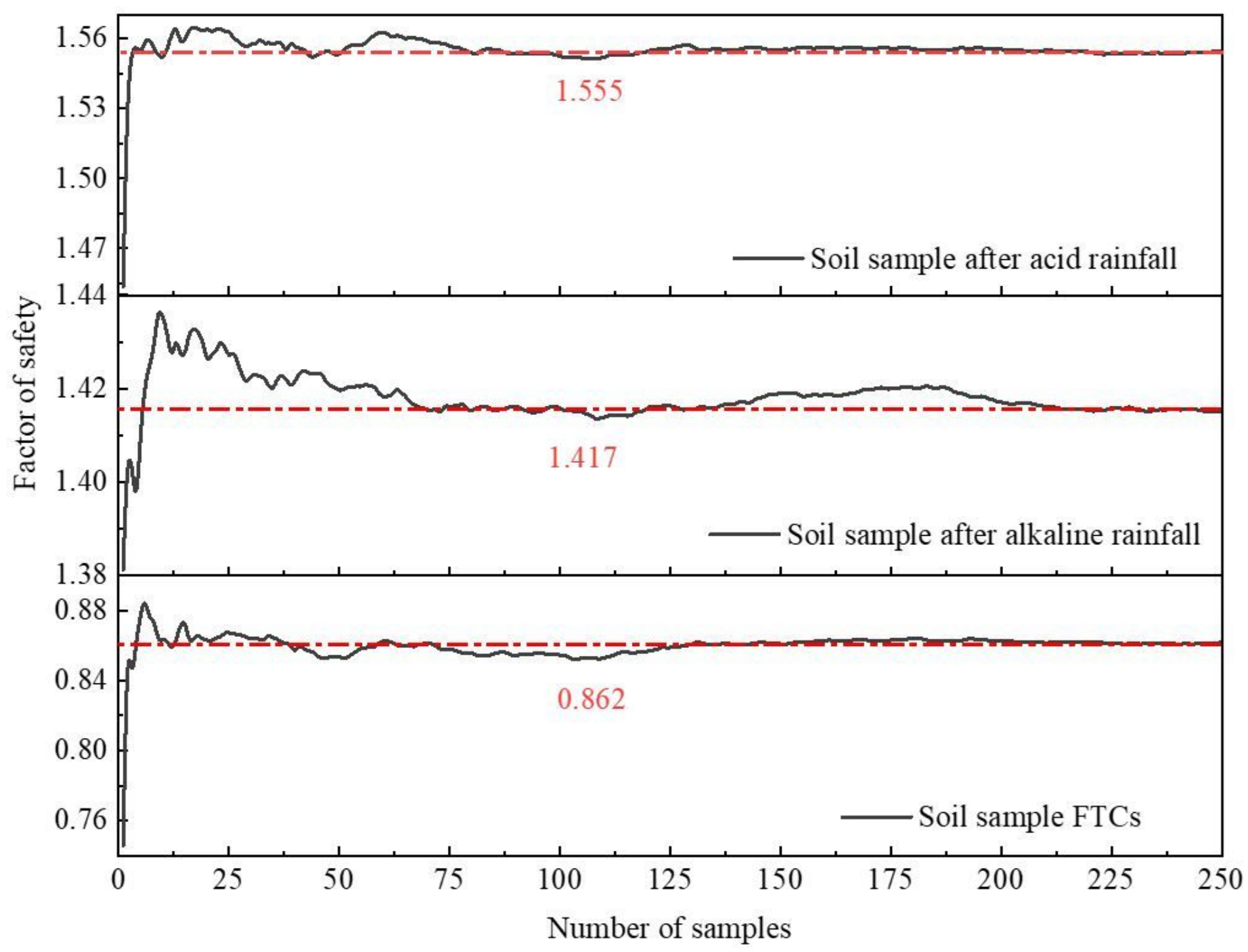

Figure 13

Convergence graph of safety factor of embankment under different conditions 


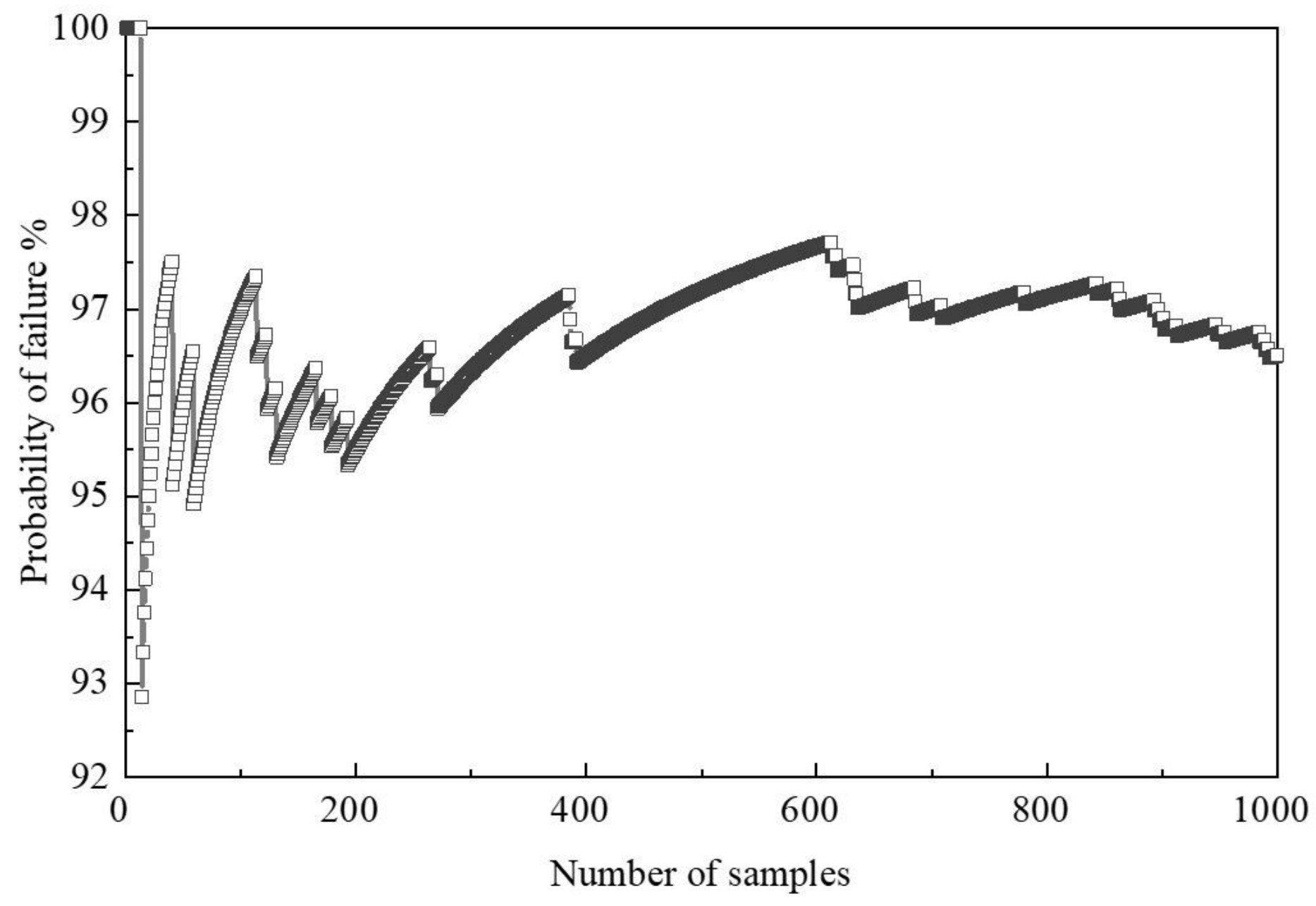

Figure 14

Convergence graph of PF of embankment under freeze-thaw cycles 